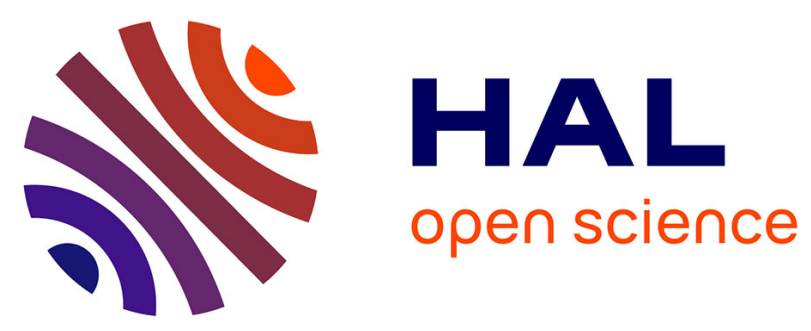

\title{
Efficient Gas and Water Vapor Barrier Properties of Thin Poly(lactic acid) Packaging Films: Functionalization with Moisture Resistant Nafion and Clay Multilayers
}

Federico Carosio, Samuele Colonna, Alberto Fina, Gaulthier Rydzek, Joseph Hemmerle, Loïc Jierry, Pierre Schaaf, Fouzia Boulmedais

\section{To cite this version:}

Federico Carosio, Samuele Colonna, Alberto Fina, Gaulthier Rydzek, Joseph Hemmerle, et al.. Efficient Gas and Water Vapor Barrier Properties of Thin Poly(lactic acid) Packaging Films: Functionalization with Moisture Resistant Nafion and Clay Multilayers. Chemistry of Materials, 2014, 26 (19), pp.5459-5466. 10.1021/cm501359e . hal-02456545

\section{HAL Id: hal-02456545 https://hal.science/hal-02456545}

Submitted on 27 Jan 2020

HAL is a multi-disciplinary open access archive for the deposit and dissemination of scientific research documents, whether they are published or not. The documents may come from teaching and research institutions in France or abroad, or from public or private research centers.
L'archive ouverte pluridisciplinaire HAL, est destinée au dépôt et à la diffusion de documents scientifiques de niveau recherche, publiés ou non, émanant des établissements d'enseignement et de recherche français ou étrangers, des laboratoires publics ou privés. 


\title{
Efficient gas and water vapor barrier properties of thin poly(lactic acid) packaging films: functionalization with mois- ture resistant Nafion and clay multilayers
}

Federico Carosio $^{1}$, Samuele Colonna ${ }^{1}$, Alberto Fina ${ }^{1}$, Gaulthier Rydzek ${ }^{2,3,4}$, Joseph Hemmerlé3,4, Loïc Jierry $^{2,5,6,7}$, Pierre Schaaf ${ }^{2,3,4,5,7,8 *}$, Fouzia Boulmedais ${ }^{2,6,7}$

${ }^{1}$ Politecnico di Torino, Alessandria, Italy.

${ }^{2}$ Institut Charles Sadron, Centre National de la Recherche Scientifique, Université de Strasbourg, Unité Propre de Recherche 22, Strasbourg, France.

${ }^{3}$ INSERM, UMR-S 1121, "Biomatériaux et Bioingénierie", Strasbourg, France

${ }^{4}$ Université de Strasbourg, Faculté de Chirurgie Dentaire; Strasbourg, France

${ }^{5}$ Université de Strasbourg, Ecole Européenne de Chimie, Polymères et Matériaux, Strasbourg, France

${ }^{6}$ University of Strasbourg Institute for Advanced Study (USIAS), Strasbourg, France

${ }^{7}$ International Center for Frontier Research in Chemistry, Strasbourg, France

${ }^{8}$ Institut Universitaire de France, Paris, France

KEYWORDS: Layer-by-Layer, polylactic acid, nafion, clay, barrier properties.

\begin{abstract}
Poly(lactic acid) (PLA) represents one of the most promising and attractive bio-based polymer for the industrial development of environmentally sustainable packaging. However, oxygen and water barrier properties of PLA based films cannot compete with those of commercially available composite multilayers. To fill this gap, we used the Layer-by-Layer deposition technique on commercially used PLA thin films (30 $\mu \mathrm{m}$ thick) in order to increase their barrier properties to oxygen and water vapor. Nanometric films were grown by alternating branched poly(ethylene imine) (BPEI), hydrophobic fluorinated polymer (Nafion) and montmorillonite clay (MMT) layers with the aim of obtaining low gas permeability in both dry and moist conditions as well as low water vapor permeability. Two different kinds of architectures were designed and successfully prepared, based on a 4 layer repeating-unit (BPEI/MMT/BPEI/Nafion), represented here as quadlayer (QL), and on a 6 layer repeating-unit ((BPEI/Nafion) $)_{2}$ BPEI/MMT), hexalayer (HL). Reduction in oxygen and water permeabilities is observed for films based on both types of repeat units. The reduction of the permeabilities increases with the number of quad and hexalayers achieving reductions in terms of oxygen permeability in both dry and humid conditions up to $98 \%$ and $97 \%$ respectively for $10 \mathrm{HL}$ and QL. Furthermore, a reduction of $78 \%$ of water vapor transmission rate through the functionalized film was obtained for these films. As far as oxygen permeability is concerned, HL films are more efficient than QL films for smaller numbers of deposition units. These properties are shown to result from the complementarity between the presence of BPEI/Nafion and MMT layers.
\end{abstract}

\section{INTRODUCTION}

Food packaging allows maintenance of products in a suitable atmosphere (e.g. limited oxygen concentration or moisture content, etc...) for the duration of its shelf life. ${ }^{1}$ To prevent gases and water vapor diffusion through the packaging, composite multilayers or metallized films are traditionally used, leading to technical problems in recycling. ${ }^{1-3}$ The use of environmentally sustainable biopolymers, such as poly(lactic acid) (PLA), represents a step forward in the reduction of environmental impact of food packaging. ${ }^{4,5}$ As far as extended shelf life is concerned, the barrier properties of the biopolymers currently available are generally poorer in comparison with those achievable with selected fossil fuel-derived materials. In order to fill this gap, nanotechnology has been exploited in the form of either layered silicate nanocomposites or nanosized coatings ${ }^{6,7}$ deposited on polymers by physical or chemical vapor processes. The presence of nanoparticles with high aspect ratio reduced the gas permeability of the materials. The best barrier properties are achieved with preferential orientation of nanoplatelets lying perpendicularly to the gas flow. ${ }^{6}$ Such highly ordered structures are very difficult to obtain. ${ }^{8}$ As a result, they are insufficient for food packaging applications (typically between $1 / 10$ to $1 / 100$ of unmodified polymer permeability). Physical vapor deposition (PVD) and chemical vapor deposition (CVD) processes guarantee low gas permeability but their performances are limited by the presence of micro- and nano-defects in the coating as well as by their tendency to crack upon film deformation during use..$^{9-13}$ 
Table 1. Oxygen and water vapor permeability, with the variation compared to the bare substrate $(\%)$, of LbL coatings in comparison with other barrier technologies.

\begin{tabular}{|c|c|c|c|}
\hline & $\begin{array}{c}\text { Oxygen } \\
\text { Permeability } \\
\text { in cc.mm } \\
/\left(\mathrm{m}^{2} \text { day } \mathrm{atm}\right)\end{array}$ & $\begin{array}{l}\text { Water vapor } \\
\text { permeability } \\
\text { in } \mathrm{g} \cdot \mathrm{mm} \\
/\left(\mathrm{m}^{2} \text { day } \mathrm{atm}\right)\end{array}$ & $\begin{array}{l}\text { Calculated } \\
\text { from } \\
\text { reference }\end{array}$ \\
\hline $\mathrm{EVOH}^{[\mathrm{a}]}$ & $0.001-0.01$ & $40-120$ & 29 \\
\hline $\begin{array}{c}\text { Polymer laminate } \\
67 \mu \mathrm{m}(\mathrm{PET} / \mathrm{EVOH} / \mathrm{PE})^{[\mathrm{b}]}\end{array}$ & 0.1 & $7-20$ & 29 \\
\hline $\begin{array}{l}\text { Metallised laminate } 62 \mu \mathrm{m} \\
\quad(\mathrm{PET} / \mathrm{Met} / \mathrm{PE})^{[\mathrm{b}]}\end{array}$ & $0.06-0.12$ & $0.7-2.1$ & 29 \\
\hline $\begin{array}{c}\mathrm{SiO}_{\mathrm{x}} \text { coating on } \\
12 \mu \mathrm{m} \mathrm{PET}{ }^{[b]}\end{array}$ & $0.006-0.06$ & $0.15-4.3$ & 29 \\
\hline $\begin{array}{l}\text { CHI/MMT LbL } \\
\text { on } 500 \mu \mathrm{mLA}^{[\mathrm{c}]}\end{array}$ & $\begin{array}{ll}0.26^{(1)} & (-98 \%) \\
9.20^{(2)} & (-40 \%)\end{array}$ & $45.6(-20 \%)$ & 27 \\
\hline $\begin{array}{l}\text { CHI/MMT LbL } \\
\text { on } 500 \mu \text { PLA }^{[d]}\end{array}$ & $<0.003$ & N.D. & 28 \\
\hline $\begin{array}{c}\text { BPEI/NFC LbL } \\
\text { on } 113 \mu \mathrm{m} \mathrm{PLA}^{[\mathrm{e}]}\end{array}$ & $1.01(-92 \%)$ & $0.26(-52 \%)$ & 30 \\
\hline $\begin{array}{c}\text { (BPEI/Nafion) })_{2} / \mathrm{BPEI} / \mathrm{MMT} \\
\text { on } 30 \mu \mathrm{m} \mathrm{PLA}^{[\mathrm{f}]}\end{array}$ & $\begin{array}{r}0.29^{(3)}(-98 \%) \\
0.47^{(4)}(-97 \%)\end{array}$ & $34.6(-97 \%)$ & $\begin{array}{l}\text { Our } \\
\text { study }\end{array}$ \\
\hline
\end{tabular}

${ }^{[a]}$ tested at $23^{\circ} \mathrm{C} 0 \%$ relative humidity (R.H.) for oxygen permeability and at $23^{\circ} \mathrm{C} 85 \%$ R.H. for water vapor permeability; ${ }^{[b]}$ tested at $23^{\circ} \mathrm{C} 50 \%$ R.H. for both oxygen and water vapor permeability; ${ }^{[\mathrm{c}} 70 \mathrm{CHI} / \mathrm{MMT}$ bilayers; oxygen permeability tested at (1) $23^{\circ} \mathrm{C} 20 \%$ R.H. and (2) $23^{\circ} \mathrm{C} 80 \%$ R.H; water vapor permeability tested at $38^{\circ} \mathrm{C} 98 \%$ R.H.; Bare PLA has an oxygen permeability of 17.9 and $15.8 \mathrm{cc} \mathrm{mm} /\left(\mathrm{m}^{2}\right.$ day atm) in conditions (1) and (2), respectively and a water vapor permeability of $56.7 \mathrm{~g} \mathrm{~mm} /\left(\mathrm{m}^{2}\right.$ day atm); [d]30 CHI/MMT bilayers; oxygen permeability tested at $23^{\circ} \mathrm{C} 0 \%$ R.H. below the low-end detection limit $\left(0.005 \mathrm{~cm}^{3} /\left(\mathrm{m}^{2}\right.\right.$ day atm $\left.)\right)$ of the instrument; Bare PLA has an oxygen permeability of $15.25 \mathrm{cc} \mathrm{mm} /\left(\mathrm{m}^{2}\right.$ day atm); not determined (N.D.). ${ }^{[\mathrm{e}]} 50 \mathrm{BPEI} / \mathrm{NFC}$ bilayers; oxygen and water vapor permeability tested at $23^{\circ} \mathrm{C} 50 \%$ R.H.; bare PLA has an oxygen permeability of $13.05 \mathrm{cc} \mathrm{mm} /\left(\mathrm{m}^{2}\right.$ day atm) and a water vapor permeability of $0.54 \mathrm{~g} \mathrm{~mm} /\left(\mathrm{m}^{2}\right.$ day atm); ${ }^{[\mathrm{f}]} 10$ depositions of (BPEI/Nafion)2/BPEI/MMT layer; oxygen permeability tested at (3) $23^{\circ} \mathrm{C} 0 \%$ R.H. and (4) $23^{\circ} \mathrm{C} 75 \%$ R.H; water vapor permeability tested at $23^{\circ} \mathrm{C}$ R.H. $75 \%$; Bare PLA has an oxygen permeability of 14.8 and $14.4 \mathrm{cc} \mathrm{mm} /\left(\mathrm{m}^{2}\right.$ day atm) in conditions (3) and (4) respectively and a water vapor permeability of $161.1 \mathrm{~g} \mathrm{~mm} /\left(\mathrm{m}^{2}\right.$ day atm).

Emerging materials such as synthetic latexes and edible coatings or techniques such as atomic layer deposition (ALD) allow improving the water barrier properties of biopolymers. ${ }^{14}$ The use of latex coatings containing exfoliated high aspect ratio nanoparticles can yield a $46 \%$ reduction in water vapor transmission rate. ${ }^{14}$ Edible coatings are currently limited by being poor moisture barriers even if encouraging results have been obtained by addition of galactomannan. ${ }^{15}$ Biopolymers treated by ALD technologies show great performances: as an example, a $50 \mathrm{~nm}$ coating made of $\mathrm{Al}_{2} \mathrm{O}_{3}$ deposited on PLA reached two order of magnitude reduction in water vapor transmission rate. ${ }^{14}$ Yet, the major drawbacks of the ALD technique are the non-atmospheric nature of the process and the high number of deposition cycles required (e.g. 500 cycles for a $50 \mathrm{~nm}$ coating) to achieve such high water transmission rate reduction.

The Layer-by-Layer (LbL) technique represents an alternative and efficient way to obtain highly oriented lamellar nanocomposites which makes it a potential solution to develop efficient gas barriers. ${ }^{16-18}$ First discovered by Iler in 1966 and extended to polyelectrolytes by Decher in $1991,{ }^{19-}$

22 this technique consists in an alternated immersion of the substrate in oppositely charged polyelectrolyte solutions or suspensions. This process leads to the alternate deposition of positively and negatively charged layers on the surface of the substrate, the interactions between the different constituents being mainly of electrostatic origin. ${ }^{23}$ Recently, LbL coatings made of clay particles proved to possess extreme oxygen barrier properties when deposited, for example, on poly(ethylene terephtalate) (PET) films ${ }^{24}$ while maintaining flexibility and mechanical properties. Grunlan et al. alternated the deposition of branched poly(ethylene imine) (BPEI) as the positive polyelectrolyte and negative sodium montmorillonite clay (MMT), leading to coatings with an oxygen transmission rate below the detection limit of commercial instruments $\left(<0.005 \mathrm{cc} /\left(\mathrm{m}^{2}\right.\right.$ day atm $)$ at $23^{\circ} \mathrm{C} 0 \%$ R.H. with 70 (BPEI/MMT) bilayers). On the same PET substrate, a four layer repetitive unit, made with three polyelectrolyte layers (BPEI/PAA/BPEI) combined with one MMT layer demonstrated the same performance in oxygen barrier with less deposited bilayers. ${ }^{25}$ Crosslinked coatings made of two polyelectrolytes have also been studied on PET film. ${ }^{26}$

The LbL technique has also been applied on PLA films using chitosan (CHI) and MMT coatings to reduce oxygen and water vapor permeability. ${ }^{27,}{ }^{28}$ Data taken from the scientific literature on LbL treated PLA films are collected in Table 1 and compared to data relative to commercial barrier coatings. ${ }^{29}$ With $70 \mathrm{CHI} / \mathrm{MMT}$ bilayers deposited on PLA films, $98 \%$ reduction in oxygen permeability was achieved at $23^{\circ} \mathrm{C}$ for relative humidity (R.H.) below $70 \%$. For higher R.H., the reduction was limited to $40 \%$. The water vapor permeability of these coatings was however limited to $20 \%$ reduction. ${ }^{27}$ Grunlan et al. succeed in improving the oxygen barrier properties of $\mathrm{CHI} / \mathrm{MMT}$ coatings at $23^{\circ} \mathrm{C} 0 \% \mathrm{R} . \mathrm{H}$. by changing the $\mathrm{pH}$ of the film buildup. ${ }^{28} \mathrm{LbL}$ barrier coatings, using BPEI and nanofibrillated cellulose (NFC), were deposited on PLA achieving $92 \%$ reduction in oxygen permeability as well as $52 \%$ reduction in water vapor permeability at $23^{\circ} \mathrm{C} 50 \%$ R.H. ${ }^{30}$ In humid conditions, the partial loss of the barrier properties of the LbL coatings are expected due to a loss in polyelectrolyte chain packing which increases the gas/vapour diffusion. ${ }^{24,25,31}$ An additional treatment of such coatings is thus required such as an additional top coating of fused wax particles, a thermal or chemical cross-linking of the films. ${ }^{25,26,32,33}$ As a consequence of such a detrimental effect exerted by water, only few published papers assessed the water vapor permeability of LbL coatings. ${ }^{27,30,33}$ Furthermore in the literature, barrier properties are typically evaluated for coatings on relatively thick substrates (few hundreds of micrometers). No study was reported so far on thin PLA films used for commercial applications (normally ranging from 20 to $60 \mu \mathrm{m}$ ) covered with LbL coatings. We report here LbL modification of thin PLA film (30 $\mu \mathrm{m}$-thick) to obtain low oxygen permeability 
in both dry and humid conditions as well as low water vapor permeability without the use of a post treatment. To this aim, BPEI, MMT and Nafion, a hydrophobic fluorinated polyanion, were used as components of the coatings. MMT layers create a tortuous path for gas molecules and Nafion layers ensure the hydrophobicity of the overall coating which should improve water impermeability.

\section{EXPERIMENTAL}

Materials. $30 \mu \mathrm{m}$-thick films made of poly(lactic acid) PLA2002D (PLA) from NatureWorks (Minnetonka, USA) were used as substrates for LbL depositions. Branched poly(ethylene imine) (BPEI, Mw 25,000 by Laser Scattering, Mn $\sim 10,000$ by Gel Permeation Chromatography, as reported in the material datasheet) and Nafion ${ }^{\circledR}$ perfluorinated resin (5 wt. \% solution in a mixture of low molecular weight aliphatic alcohols and $45 \%$ water) were purchased from Sigma-Aldrich (Milwaukee, WI). Sodium montmorillonite (MMT) was purchased from Southern Clay, Inc. (USA) and used as received. Ethanol was purchased from Sigma Aldrich (Milwaukee, WI). 18.2 M $\Omega$ deionized water, supplied by a Q20 Millipore system was used for suspension and solution preparation.
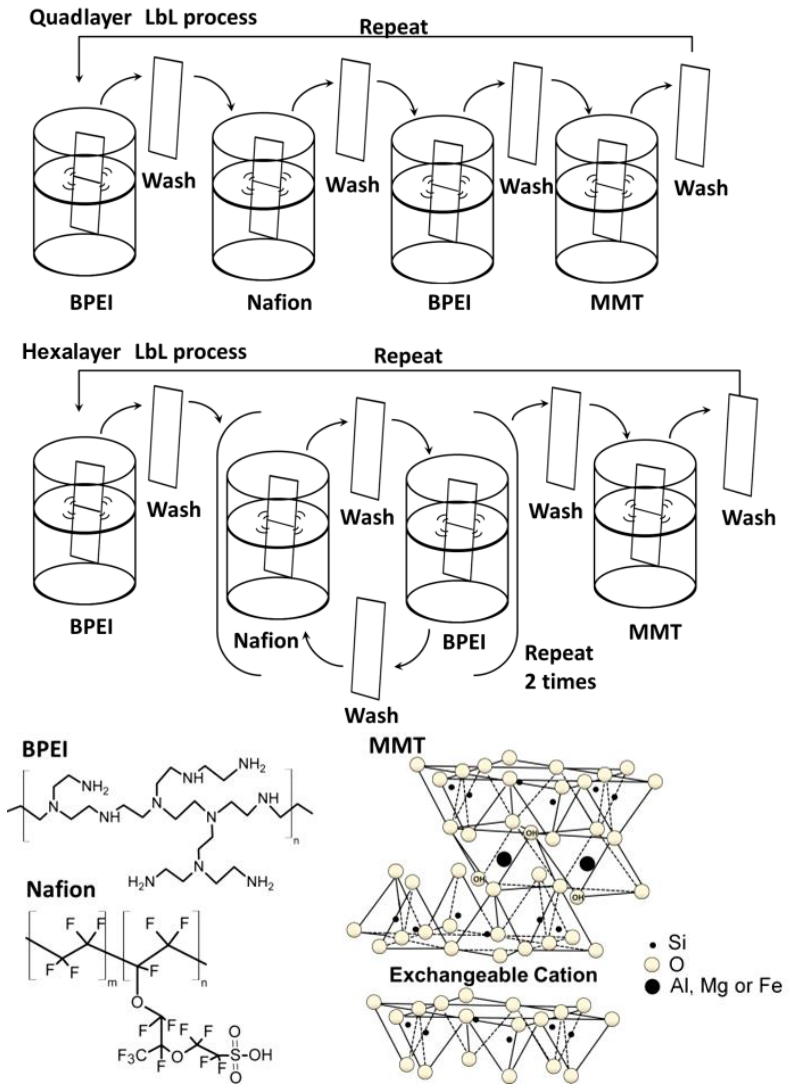

Figure 1. Schematic representation of the LbL deposition sequences adopted for the quadlayer BPEI/Nafion/BPEI/MMT (QL) and hexalayer (BPEI/Nafion)2/BPEI/MMT (HL) Nafion based architectures.

BPEI and Nafion solutions were prepared at 0.1 and $0.2 \%$-wt in $50 / 50 \mathrm{v} / \mathrm{v}$ water/ethanol, respectively. The experiments were performed in 50/50 v/v water/ethanol solutions because this water/ethanol proportion is close the one giving the highest hydrophobicity of BPEI/Nafion multi- layers. ${ }^{34}$ MMT suspensions were prepared at $0.2 \%$-wt. in water and the $\mathrm{pH}$ was set to $\mathrm{pH} 10$ by addition of $\mathrm{NaOH}$ ).

Layer by layer deposition. A first layer of BPEI was deposited on PLA substrates by dipping for 5 min into a $0.1 \%$ wt. BPEI water solution followed by a rinsing step of $5 \mathrm{~min}$ in water. In the following, PLA substrates were alternately immersed into positively charged (BPEI) and negatively charged (Nafion, MMT) solutions for $5 \mathrm{~min}$ (Figure 1). These deposition steps were performed with $(50 / 50 \mathrm{v} / \mathrm{v})$ ethanol/water BPEI and Nafion solutions and water solutions at $\mathrm{pH} 10$ for MMT as stated previously. (50/50 v/v) water/ethanol solutions were used for the rinsing steps after each BPEI and Nafion deposition step and deionized water at pH 5-6 was used after each MMT adsorption step. In both cases, the rinsing time was set to $5 \mathrm{~min}$. Three different kinds of architectures were deposited: (i) bilayers (denoted as BL) of BPEI and Nafion, (ii) quadlayers (denoted as QL) BPEI/Nafion/BPEI/MMT and (iii) hexalayers (denoted as HL) (BPEI/Nafion) $)_{2} / \mathrm{BPEI} / \mathrm{MMT}$. The adsorption processes were repeated up to $4,6,8$ or 10 of QL or HL.

Ellipsometry. Measurements of the film thickness were carried out with a PLASMOS SD 2300 ellipsometer operating at the single wavelength of $632.8 \mathrm{~nm}$ and a constant incidence angle of $70^{\circ}$. The films were built on silicon wafers. Due to the inherent limit of ellipsometry to simultaneously determine the refractive index and the film thickness for very thin films, the refractive index of all films was assumed to be constant and fixed at $n=1.465$. While this procedure will lead to slightly incorrect values with respect to the absolute film thicknesses, it allows for the quick and precise determination of relative film thicknesses. Thickness values obtained with the assumption of a fixed refractive index for all films are of better precision than required for the comparison of film growth data used in this article. For each studied substrate, 10 different thickness measurements were randomly taken on different film regions over an area of a few $\mathrm{cm}^{2}$. The measurements were performed in the dry state after drying the films under a stream of nitrogen.

Atomic force microscopy (AFM) measurement. AFM images were obtained in contact mode in dry conditions with the Nanoscope IV from Veeco (Santa Barbara, CA). The images were carried out with silicon nitride cantilevers (spring constant $0.03 \mathrm{~N} / \mathrm{m}$, model MSCTAUHW, Veeco, CA). Several scans were performed over a given surface area. These scans had to give reproducible images to ascertain that there is no sample damage induced by the tip. Deflection and height mode images are scanned simultaneously at a fixed scan rate $(2 \mathrm{~Hz})$ with a resolution of $512 \times 512$ pixels. Data evaluation was performed with the NanoScope software version 5.31r1 (Digital Instruments, Veeco). The film buildup was made on silicon wafers and film thicknesses were measured by using the "scratch" method. Profilometric section analyses of a scratched film allowed determining precisely the film quality and film thickness over the scanned area. The scratches were achieved with a plastic cone tip and were always imaged perpendicular to the fast scan axis. The profiles correspond to a cross section along this axis. 

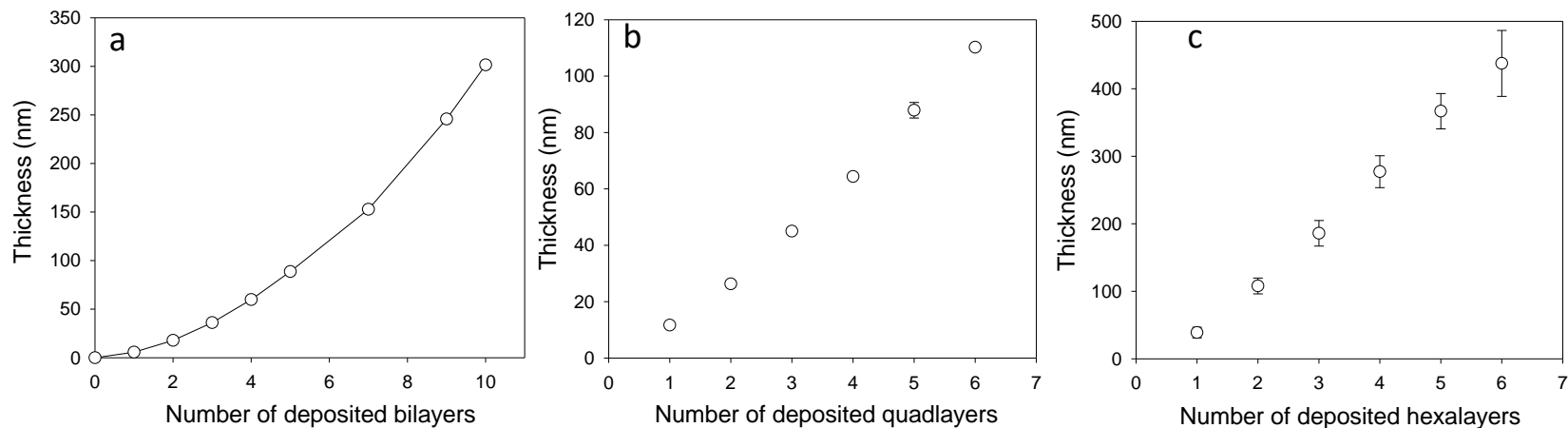

Figure 2. Evolution of the film thickness, measured by ellipsometry, of (a) (BPEI/Nafion) 10 as a function of the number of bilayers, (b) (BPEI/MMT/BPEI/Nafion $)_{6}$ as a function of the number of quadlayers and (c) ((BPEI/Nafion) $)_{2}$-BPEI/MMT) $)_{6}$ as a function of the number of hexalayers. The data represent the mean and the standard deviation of three experiments. In Figure $2 \mathrm{a}$ and $2 \mathrm{~b}$, the values of the standard deviation are smaller or similar size compared to the reported symbol. The data are gathered in Table S1, S2 and S3 in SI.

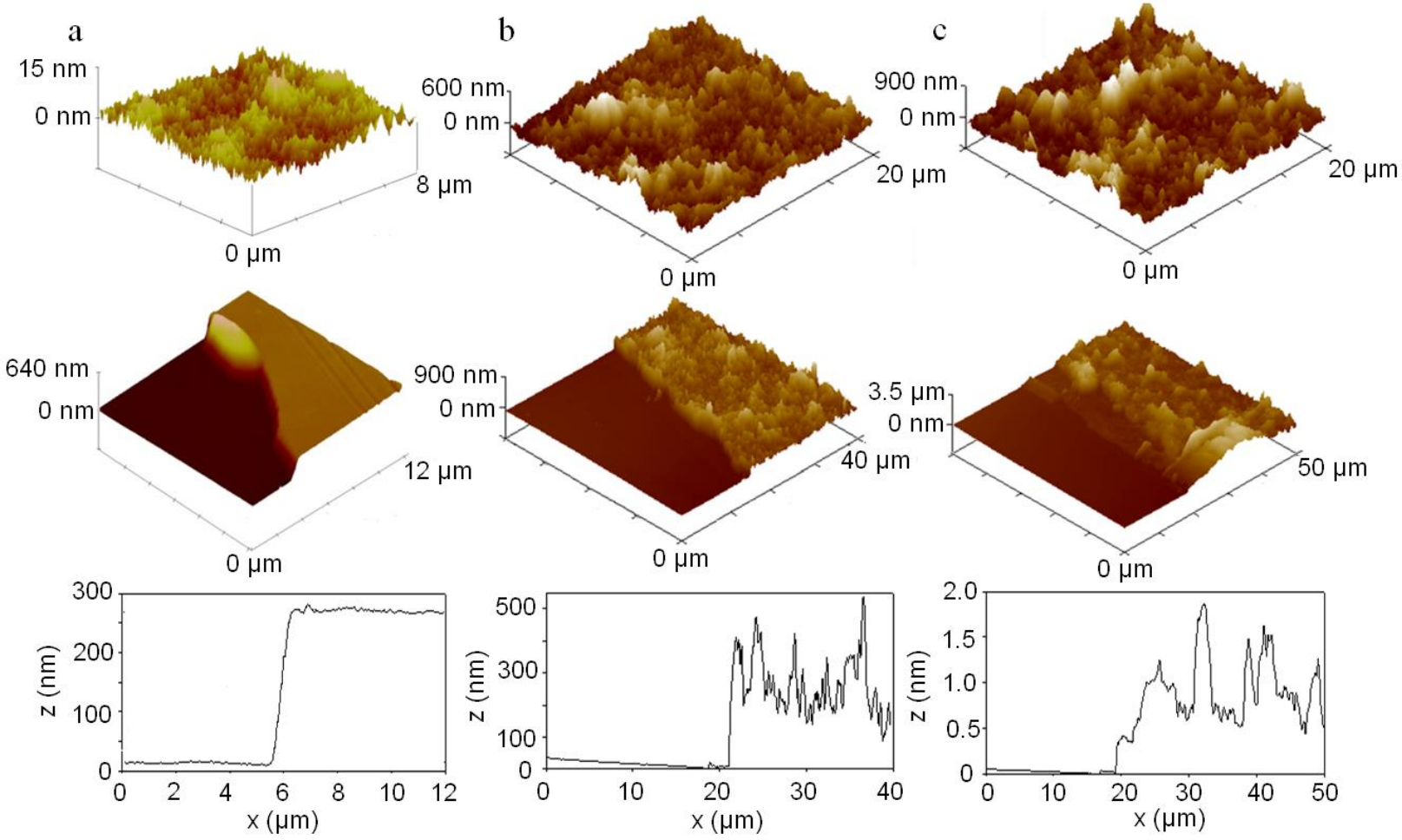

Figure 3. 3D AFM images, obtained in contact mode in dry state, of (a) (BPEI/Nafion) $)_{10}$, (b) (BPEI/MMT/BPEI/Nafion) 10 (c) ((BPEI/Nafion) $)_{2}$-BPEI/MMT) ${ }_{10}$ LbL films unscratched (first row), scratched (second row) and profilometric section (third row).

Fourier transformed infrared spectroscopy in attenuated total reflectance. Attenuated Total Reflectance (ATR) Fourier transformed infrared spectroscopy (FTIR) spectra of uncoated and coated PLA films were recorded at room temperature in the range $4000-700 \mathrm{~cm}^{-1}\left(16\right.$ scans and $4 \mathrm{~cm}^{-1}$ resolution) using a Frontier FT-IR/FIR spectroscopy (Perkin Elmer, Italy) equipped with a $\mathrm{Ge} / \mathrm{Ge}$ crystal (depth of penetration $0.65 \mu \mathrm{m}$, as stated by the producer) by applying a constant pressure between sample and crystal. To follow the increase of the IR peaks, a difference spectrum was calculated by subtracting the spectrum of the uncoated PLA to the LbL coated ones.

X-ray diffraction. XRD measurements were performed on LbL treated PLA films with a X'Pert Philips (NL) X-ray diffractometer $(\lambda(\mathrm{CuK} \alpha)=1.540562 \AA)$ in configuration $2 \theta / \theta .1-10^{\circ} 2 \theta$ range and a scan rate of $0.5^{\circ} / \mathrm{min}$.

Transmission electron microscopy. Samples were directly embedded in Epon 812 epoxy resin (Embedding Kit SIGMA Reference 45359-1EA-F; Euromedex, Souffelweyersheim, France). Ultrathin sections of $100 \mathrm{~nm}$ in thickness were performed by using a Reichert Jung Ultracut E automatic ultramicrotome (Leica Microsystème, Nanterre, France) equipped with a diamond knife and mounted on 100 mesh formvar covered and carbon coated grids. Ultrathin sections were observed without any staining. Transmission electron microscopy images were obtained with a Philips EM 208 instrument (FEI Company, Eindoven, The Netherlands) operating with an accelerating voltage of $70 \mathrm{kV}$. Micrographs were recorded on Kodak SO163 films. 
Contact angle. Contact angle measurements were performed on a KSV CAM 200 (Nordtest, Italy) using deionized water. For each sample, the measurement was repeated three times.

Oxygen permeability and water vapor transmission measurements. Oxygen permeability and water vapor transmission rate were measured using an Extraperm apparatus (Extra solutions, Italy) on two different samples of 50 $\mathrm{cm}^{2}$. The oxygen permeability tests were performed at $23^{\circ} \mathrm{C}$ in dry and humid conditions, $0 \%$ and $75 \%$ Relative Humidity $(\mathrm{RH})$ respectively. The water vapor transmission was measured at $23^{\circ} \mathrm{C} 75 \%$ R.H on two different samples of $2.27 \mathrm{~cm}^{2}$. The experimental error was found to be within \pm 5 and $\pm 2.5 \%$ for oxygen permeability and water vapor permeability, respectively.

\section{RESULTS AND DISCUSSION}

Coating growth characterization. Three different types of coatings BPEI/Nafion bilayers (BL), BPEI/MMT/BPEI/ Nafion (QL) and (BPEI/Nafion) $)_{2}$-BPEI/MMT (HL) were studied. The films were first built on silicon wafers in order to follow the film thickness by ellipsometry. An exponential growth is observed for BPEI/Nafion films leading to $300 \mathrm{~nm}$ thick films after 10 bilayers (Figure 2a). On the contrary, quadlayers and hexalayers films showed a linear growth with a distance between two MMT layers of about $20 \mathrm{~nm}$ for quadlayers, and about $80 \mathrm{~nm}$ for hexalayers (Figure $2 \mathrm{~b}$ and $2 \mathrm{c}$ ). The buildup of the three types of coating is reproducible with a small standard deviation in the thickness values (Table S1, S2 and S3 in Supporting Information (SI)). The films constituted of $10 \mathrm{BL}, 10 \mathrm{QL}$ and $10 \mathrm{HL}$, are homogeneous (Figure 3) and cover the whole substrate (Figure 3, profilometric section). Film thicknesses, measured by AFM (table 2), are in accordance with those obtained by ellipsometry (figure 2). (BPEI/Nafion) ${ }_{10}$ films are smooth with a roughness of about $\pm 2 \mathrm{~nm}$ for a thickness of $288 \mathrm{~nm}$. (BPEI/MMT/BPEI/ Nafion $)_{10}$ and ((BPEI/Nafion) $)_{2}-$ $\mathrm{BPEI} / \mathrm{MMT})_{10}$ films have a higher roughness likely due to the presence of MMT. The roughness increases with the number of QL/HL, from $21 \mathrm{~nm}$ for 6QL to $107 \mathrm{~nm}$ for 10 $\mathrm{QL}$, and from 32 for $6 \mathrm{HL}$ to $182 \mathrm{~nm}$ for $10 \mathrm{HL}$.

Table 2. Thicknesses and roughnesses of Nafion/MMT based multilayer films, measured by AFM.

\begin{tabular}{ccc}
\hline Film & Thickness $(\mathrm{nm})$ & Roughness $(\mathrm{nm})$ \\
\hline 10 BL: (BPEI/Nafion) $_{10}$ & 288 & 2 \\
6 QL: (BPEI/Nafion/BPEI/MMT) & 110 & 21 \\
10 QL: (BPEI/Nafion/BPEI/MMT) $)_{10}$ & 210 & 107 \\
6 HL: ((BPEI/Nafion) $\left.)_{2} / \mathrm{BPEI/MMT}\right)_{6}$ & 380 & 32 \\
10 HL: ((BPEI/Nafion $\left.)_{2} / \mathrm{BPEI/MMT}\right)_{10}$ & 600 & 182
\end{tabular}

Characterization of the assemblies on PLA. Next, MMT and Nafion based films were built on thin PLA substrates. XRD, FTIR spectroscopy, contact angle measurement and TEM were used to characterize the treated PLA films. XRD measurements have been exploited in order to determine possible changes in MMT interlayer distances when deposited in LbL. Figure $4 \mathrm{a}$ shows XRD patterns performed on dry MMT powder as well as on $10 \mathrm{QL}$ and 10 HL deposited on PLA films. $10 \mathrm{QL}$ and $10 \mathrm{HL}$ films have the highest number of MMT layers and thus are expected to yield the best diffraction signal among the treated samples. Neat MMT shows the characteristic peak at $7.3^{\circ}(2 \theta)$ due to the basal spacing between each MMT nanoplatelet (i.e. 1.2 $\mathrm{nm}$ ) which is consistent with the literature. ${ }^{35}$ As far as LbL treated samples are concerned, both $10 \mathrm{QL}$ and $10 \mathrm{HL}$ films show a shift of the MMT low-angle peak to $\sim 6.5^{\circ}$ which is correlated to a distance increase from 1.2 to $1.4 \mathrm{~nm}$. Such shift demonstrates that the MMT nanoplatelets exhibit lamellar stacking during the LbL deposition, with stacks consisting of several MMT layers deposited at each clay adsorption step (bottom of Figure 4b). The increase in interlayer distance can be ascribed to the hydrated state of the adsorbed MMT stacks. Indeed, hydrated MMT can exhibit inter-sheet distances ranging from 1.2 and $1.6 \mathrm{~nm}{ }^{36}$ This distance cannot be related to the distances in between each deposited clay layer, corresponding to the thickness of BPEI/Nafion/BPEI $(20 \mathrm{~nm})$ for QL films or (BPEI/Nafion $)_{2}-$ BPEI $(80 \mathrm{~nm})$ for HL films. These latter thicknesses fall beyond the detection range of the adopted XRD conditions. The XRD signal shift reflects the hydration degree of the MMT stacks which directly affects the spacing between the sheets constituting each MMT nanoplatelets. Figure 4b schematically represents the structure of the QL and HL architectures underlying the differences between the MMTstack layers distances (due to the other polyelectrolytes) and the internal distance in a single MMT-stack layer (due to the hydrate state of MMT).

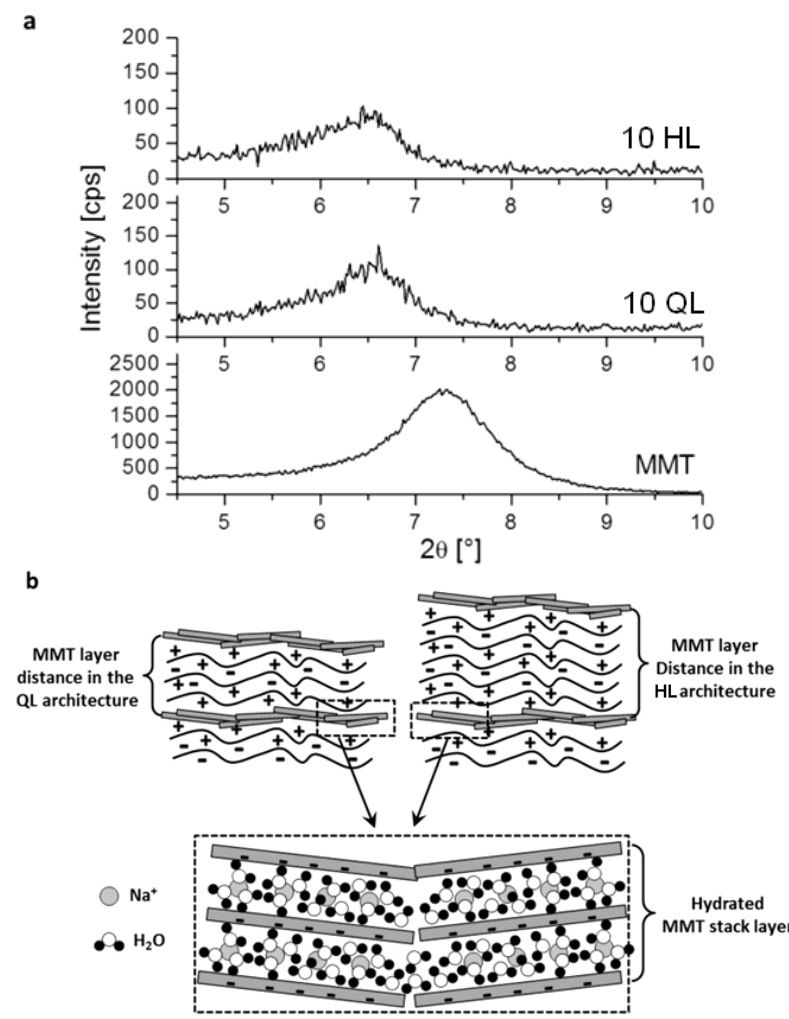

Figure 4. a) XRD patterns of MMT and PLA films coated with $10 \mathrm{QL}$ and $10 \mathrm{HL}$ of Nafion/MMT based multilayers; b) schematic representation of hydrated MMT stack layer.

Figure 5a reports the collected FTIR-ATR spectra of bare PLA in comparison with PLA treated by Nafion-MMT based QL and HL films. Characteristic signals of bare PLA 
are well distinguishable in all the samples, in particular the band centered at $1745 \mathrm{~cm}^{-1}$ for ester $\mathrm{C}=\mathrm{O}$ stretching and bands at $1250-1050 \mathrm{~cm}^{-1}$ related to $\mathrm{C}-\mathrm{O}-\mathrm{C}$ and $\mathrm{C}-\mathrm{O}$ stretching. ${ }^{37}$ In the spectra of LbL-coated samples, the intensity of PLA signals are significantly attenuated compared to bare PLA due to the presence of the coating. FTIR spectra are representative of the thin layer on the surface of the substrate. The presence of the deposited coatings is confirmed by the characteristic vibration bands of Nafion (1240 and $1170 \mathrm{~cm}^{-1}, \mathrm{C}-\mathrm{F}$ asymmetric and symmetric stretching) and MMT (1030 $\mathrm{cm}^{-1}$, Si-O-Si stretching). ${ }^{38,39}$ As expected, C-F vibration bands can be better appreciated from the spectra of HL coated samples, where the number of Nafion layers is increased, compared to the QL coated samples. The characteristic peak of MMT is easily detected for all the studied films $\left(1030 \mathrm{~cm}^{-1}\right)$. The presence of a broad band centered near $1650 \mathrm{~cm}^{-1}$ for all the treated samples is due to the symmetric and asymmetric stretching vibration of protonated BPEI amines. ${ }^{39}$ The difference of the FTIR spectra of each treated PLA substrate with bare PLA allows following the increase of the Nafion intensity signals during the QL and HL step depositions (Figure 5b). The negative bands at 1185 and $1075 \mathrm{~cm}^{-1}$ are due to the attenuation of PLA peaks due to the limited penetration depth of the IR signal by ATR.

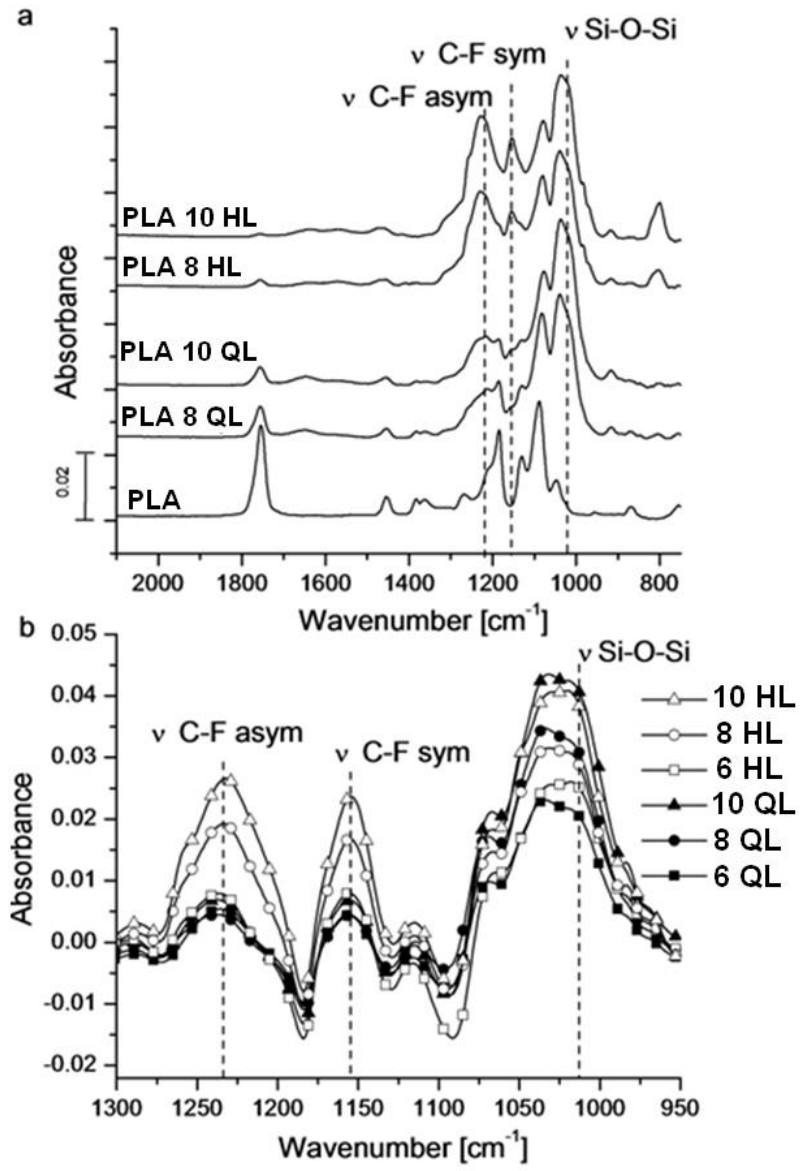

Figure 5. (a) ATR spectra of PLA films treated by QL and HL of Nafion/MMT based multilayers. (b) Difference between the spectra of each treated film and bare PLA.

TEM cross-section images of PLA coated by $10 \mathrm{HL}$ and $10 \mathrm{QL}$ are shown in Figure 6a and 6b. In order to be ob- served, PLA had to be included in an epoxy resin. This inclusion induced a degradation of the PLA (Figure S1 in SI). This could explain the holes that appear in the LbL coating. During the cutting procedure, some portions of the coating may also be removed. There are fewer and smaller holes in the case of HL coatings compared to QL ones which could be explained by a better cohesion of the coatings with higher number of polyelectrolyte layers between two MMT layers. TEM images show clearly the presence of oriented clays mostly parallel to the surface and deposited in several clay lamellae, justifying the presence of the diffraction peaks in XRD. Contact angle measurements have been performed on PLA coated with LbL and bare PLA to evaluate the wettability property of the coating (Figure S2 in SI). Bare PLA yields a contact angle of $76 \pm 2^{\circ}$ typical of a polyester. The hydrophobicity increases when multilayers containing Nafion are deposited on PLA and reaches the highest value of $102 \pm 1^{\circ}$ for $10 \mathrm{HL}$. A slight reduction, of the contact angle has been detected for $6 \mathrm{QL}\left(70 \pm 2^{\circ}\right)$. This can be ascribed to the presence of BPEI and MMT in the film along with the low Nafion content.
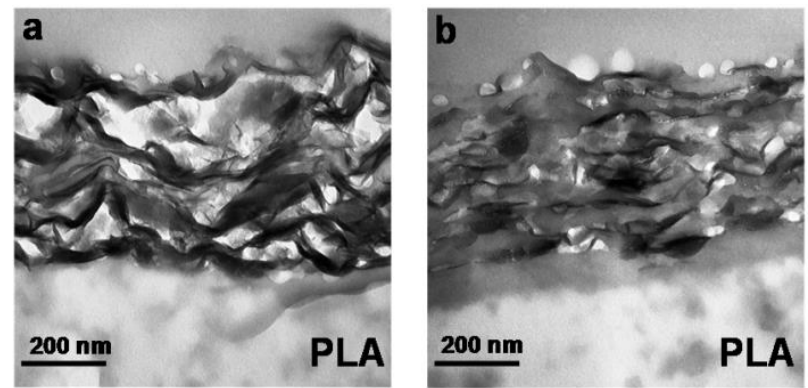

Figure 6. TEM cross-section images of (a) 10 QL and (b) 10 HL of Nafion/MMT based multilayers deposited on PLA.

Oxygen and water vapor barrier properties of the treated PLA thin film. As moisture plays an important role in packaging, the oxygen permeability has been evaluated in both dry and humid conditions. Figure 7 summarizes oxygen permeability in dry and humid conditions for both bare PLA and PLA treated with QL and HL films. The values of the oxygen permeability for the different coatings, together with the reduction percentage compared to bare PLA, are presented in Table S4 in SI. In dry condition, bare PLA films show an oxygen permeability of 14.8 $\mathrm{cc} \cdot \mathrm{mm} /\left(\mathrm{m}^{2} \cdot\right.$ day $\cdot a t m$. The permeability of QL treated PLA decreases when the number of QL increases, reaching 0.26 $\mathrm{cc} \cdot \mathrm{mm} /\left(\mathrm{m}^{2} \cdot\right.$ day $\left.\cdot \mathrm{atm}\right)$ with $10 \mathrm{QL}$. This corresponds to a reduction of $98 \%$ compared to bare PLA. In the case of HL treated PLA, the same reduction of the oxygen permeability is obtained for $10 \mathrm{HL}$. Such findings can be ascribed to the high barrier efficiency of both architectures in combination with the instrument sensitivity. The detection limit of the adopted instrument is not able to discriminate between 10 QL and $10 \mathrm{HL}$ at such low permeability values. For smaller numbers of deposited repetitive units, HL films appear more efficient than QL films. For example, $4 \mathrm{HL}$ films, corresponding to 24 deposition steps in total, have a higher barrier property compared to 6 QL films that have the same total number of deposition steps. Permeability of the Nafion based coatings does not only dependent on the number of nanoclay layers deposited. The higher efficiency for HLs 
coatings can be ascribed to the higher interlayer distance between each clay layer with respect to the QL system ( 80 $\mathrm{nm}$ for HL films vs $20 \mathrm{~nm}$ for QL films). In the case of BPEI/MMT films, it has been reported that a significant enhancement of the oxygen barrier properties is achieved by increasing the distance between each clay layer. ${ }^{24}$ Diffusion of oxygen molecules is more difficult through clay-based assemblies with high distance in between MMT layers. 20 bilayers of BPEI/Nafion can yield a reduction of 22 and $25 \%$ in dry and $75 \% \mathrm{RH}$ conditions, respectively. This barrier property of the polyelectrolyte film is therefore proposed to provide an additional barrier affect.

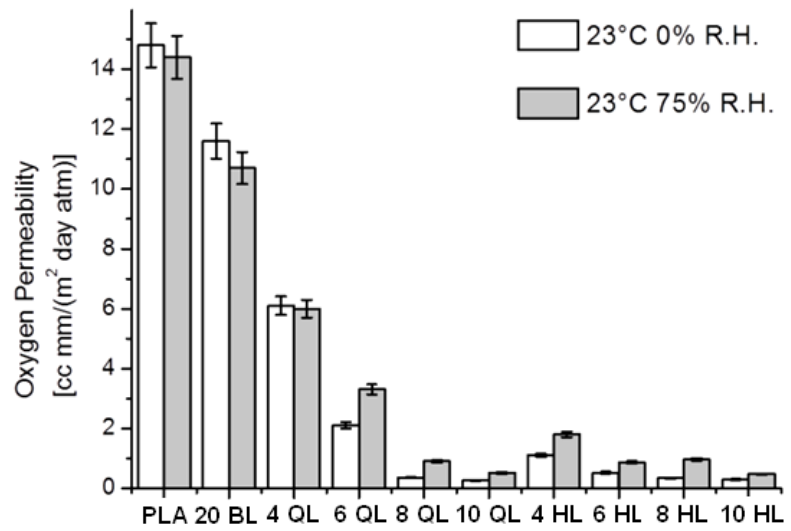

Figure 7. Oxygen permeability in dry and humid conditions of bare PLA and PLA treated by Nafion/MMT based multilayers. The data represent the mean and the standard deviation of two different samples of $50 \mathrm{~cm}^{2}$. The experimental error was found to be within $\pm 5 \%$.

In humid conditions, the oxygen permeability of QL and HL films is almost the same as at $0 \%$ R.H. Indeed, $10 \mathrm{QL}$ and $10 \mathrm{HL}$ treated PLA films present a reduction of $96 \%$ and $97 \%$ in oxygen permeability compared to bare PLA film, respectively. For comparison in the case of $7 \mathrm{QL}$ BPEI/PAA/BPEI/MMT films, a two order of magnitude loss in oxygen permeability is observed from dry to humid testing conditions. ${ }^{25}$ The ability of our QL and HL treated PLA films to withstand humid environment is ascribed to the Nafion layers. Our experiments thus show the complementarity of BPEI/Nafion and MMT layers to achieve good oxygen barrier effects in both dry and humid conditions. The prepared coatings have also been tested for water vapor permeability (Figure 8). Water vapor permeability values of the different coatings and the reduction percentage compared to bare PLA are reported in Table S5 in SI. Similarly to oxygen permeability, the LbL-coated films show a significant reduction in water vapor permeability that is proportional to the number of QL or HL deposited. 78\% reduction in water permeability is obtained with $10 \mathrm{HL}$ treated PLA films compared to bare PLA film. 20 bilayers of Nafion/PEI treated PLA films present a $33 \%$ reduction of water permeability. Here too, the barrier effect can be ascribed to both Nafion and clay layers. Nafion layers increase the hydrophobicity of the coating (Figure S2 in SI). Under water vapor exposure, clay nanoplatelets are probably maintained parallel to the surface (i.e. perpendicular to gas flux) explaining the small influence of the relative humidity on oxygen permeability.

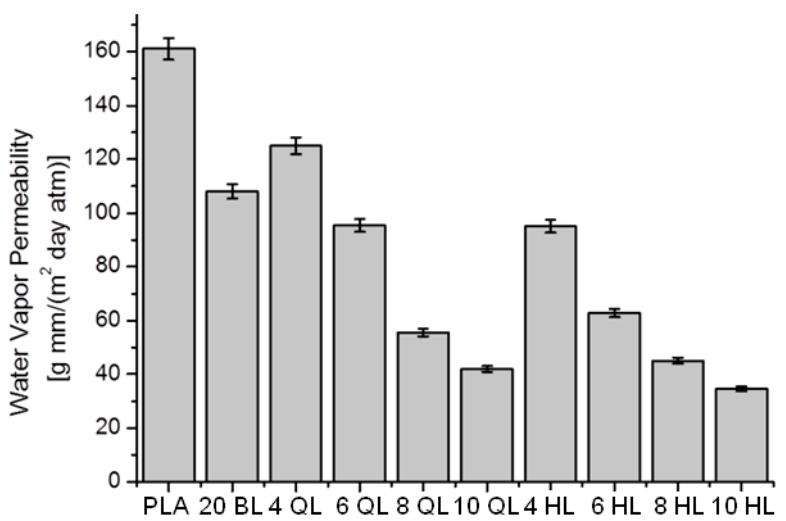

Figure 8. Water vapor permeability of bare PLA and PLA treated by Nafion/MMT based multilayers. The data represent the mean and the standard deviation of two different samples of $50 \mathrm{~cm}^{2}$. The experimental error was found to be within $\pm 2.5 \%$.

\section{CONCLUSIONS}

In summary, we have successfully created oxygen and water vapor barriers composed of commonly used thin PLA films treated by BPEI, Nafion and MMT LbL coatings. The use of two architectures, QL and HL, allows highlighting the complementarity of both BPEI/Nafion and MMT layers on the oxygen permeability in dry and humid conditions. In comparison with previous works on LbL treated PLA, ${ }^{27,30}$ these QL and HL architectures showed an enhanced reduction in oxygen permeability (up to $-98 \%$ ) that is maintained under humid testing conditions $(-97 \%)$ as well as an improvement in the lowering of water vapor permeability($78 \%$ ) (Table 1). The implementation of both oxygen and water vapor barrier properties in one coating represents an interesting and promising result for packaging applications. Moreover, the achieved barrier performances can be tuned as a function of the application requirements by choosing the number of repetitive units deposited.

\section{ASSOCIATED CONTENT}

Supporting Information Available: Table of the thickness (mean and the standard deviation) of Nafion/MMT based LbL; TEM cross-section of uncoated PLA; Water contact angle measurements of bare PLA and PLA treated by Nafion/MMT based LbL; Table of the oxygen permeability values of bare PLA and Nafion/MMT based LbL treated PLA; Table of the water vapor permeability of bare PLA and Nafion/MMT based LbL treated PLA. This material is available free of charge via the Internet at http://pubs.acs.org.

\section{AUTHOR INFORMATION}

\section{Corresponding Author}

* Prof. P. Schaaf,

INSERM, UMR-S 1121, "Biomatériaux et Bioingénierie", 11 rue Humann, F-67085 Strasbourg Cedex, France

E-mail: pierre.schaaf@unistra.fr

\section{Author Contributions}

The manuscript was written through contributions of all authors. All authors have given approval to the final version of the manuscript.

\section{ACKNOWLEDGEMENTS}


Jean-Laurent Perin and Eloïse Gaillard are acknowledged for their technical support. G.R. is supported by a fellowship from the "Ministère de la Recherche et de la Technologie". MPNS COST Action MP1105 is acknowledged for his financial support. Professor Giovanni Camino is also acknowledged for the fruitful discussion.

\section{ABBREVIATIONS}

EVOH, Ethylene vinyl alcohol; PET, polyethylene terephthalate; PE, Polyethylene; Met, Vacuum-deposited aluminium layer, PLA: Polylactic acid; BPEI, branched poly(ethylene imine); MMT, sodium montmorillonite clay; OTR, oxygen transmission rate; AFM, atomic force microscopy; TEM, transmission electron microscopy; ATR, Attenuated Total Reflectance; FTIR, Fourier transformed infrared spectroscopy; XRD, X-ray diffraction.

\section{REFERENCES}

(1) Massey, L. K. Permeability properties of plastics and elastomers - A guide to packaging and barrier materials, PDL handbook series: Norwich, NY, 2003.

(2) Jamieson, E. H. H.; Windle, A. H. J. Mater. Sci. 1983, 18,

64.

(3) Felts, J. T. J. Plast. Film Sheet. 1993, 9, 201.

(4) Mohanty, A. K.; Misra, M.; Hinrichsen, G. Macromol. Mater. Eng. 2000, 276/277, 1.

(5) Bioplastics, Frequently asked questions; European Bioplastics, Germany 2008.

(6) Ray, S. S.; Okamoto, M. Prog. Polym. Sci. 2003, 28, 1539.

(7) Krug, T. G. In: Transparent barriers for food packaging.

Proc. 33th Soc. Vacuum coaters annual conf., SVC, 163, 1990.

(8) Nielsen, L. J. Macromol. Sci. Chem. 1967, A1, 929.

(9) Bucklow, I.; Butler P. Materials World, August 14, 2000.

(10) Chatham, H. Surf. Coat. Technol. 1996, 78, 1.

(11) Rossi, G.; Nulman, M. J. Appl. Phys. 1993, 74, 5471.

(12) Henry, B. M.; Roberts, A. P.; Grovenor, C. R. M.; Sutton, A. P.; Briggs, G. A. D.; Tsukahara, Y. M. Proc. 41st Society of Vacuum Coaters Annual Conference, Boston, SVC, 434, 1998.

(13) Erlat, A. G.; Spontak, R. J.; Clarke, R. P.; Robinson, T. C.; Haaland, P. D.; Tropsha, Y. J. Phys. Chem. B 1999, 103, 6047.

(14) Grewal, R.; Sweesy, W.; Jur, J. S.; Willoughby, J. In Functional Materials from Renewable Sources; Liebner, F et al.; ACS Symp. Ser. ACS: Washington, DC, 2012.

(15) Cerqueira, M. A. J. Agric. Food Chem. 2009, 57, 1456.

(16) Kleinfeld, E. R.; Ferguson, G. S. Science 1994, 265, 370.
(17) Lvov, Y.; Ariga, K.; Ichinose, I.; Kunitake, T. Langmuir 1996, 12,3038 .

(18) Kotov, N. A.; Haraszti, T.; Turi, L.; Zavala, G.; Geer, R. E.; Dékány, I.; Fendler, J. H. J. Am. Chem. Soc 1997, 119, 6821.

(19) Iler, R. K. J. Colloid Interface Sci.1966, 21, 569.

(20) Decher, G.; Hong, J. D. Makromol. Chem., Macromol. Symp. 1991, 46, 321.

(21) Decher, G.; Maclennan, J.; Sohling U.; Reibel, J. Thin Solid Films 1992, 210/211, 504.

(22) Decher, G. Science 1997, 277, 1232.

(23) Bernt, P.; Kurihara, K.; Kunitake, T.; Langmuir 1992, 8 , 2486.

(24) Priolo, M. A.; Gamboa, D.; Grunlan, J. C. Appl. Mater. Interf. 2010, 2, 312 .

(25) Priolo, M. A.; Gamboa, D.; Holder, K. M.; Grunlan, J. C. Nano Lett. 2010, 10, 4970.

(26) Yang, Y.; Haile, M.; Park, Y. T.; Malek, F. A.; Grunlan, J. C. Macromolecules 2011, 44, 1450.

(27) Svagan, A. J.; Åkesson, A.; Cárdenas, M.; Bulut,S.; Knudsen, J. C.; Risbo, J.; Plackett, D. Biomacromolecules, 2012, 13, 397.

(28) Laufer, G.; Kirkland, C.; Cain, A. A.; Grunlan, J. C. Appl. Mater. Interfaces 2012, 4, 1643.

(29) Lange, B. J.; Wyser, Y.; Packag. Technol. Sci. 2003, 1, 149.

(30) Aulin, C.; Karabulut, E.; Tran, A.; Wågberg, L.; Lindström, T. ACS Appl. Mater. Interfaces 2013, 5, 7352.

(31) Nolte, A. J.; Treat, N. D.; Cohen, R. E.; Rubner, M. F. Macromolecules $\mathbf{2 0 0 8 , 4 1 , 5 7 9 3 .}$

(32) Glinel, K.; Prevot, M.; Krustev, R.; Sukhorukov, G. B.; Jonas, A. M.; Möhwald, H. Langmuir 2004, 20, 4898.

(33) You-Hao, Y.; Bolling, L.; Haile, M.; Grunlan, J. C. RSC Advances, 2012, 2, 12355.

(34) S. Sangribsub, P. Tangboriboonrat, T. Pith, G. Decher, Polymer Bulletin 2005, 53, 425

(35) Laachachi, A.; Ball, V.; Apaydin, K.; Toniazzo, V.; Ruch, D. Langmuir 2011, 27, 13879.

(36) Zheng, Y.; Zaoui, A. Solid State Ionics 2011, 203, 80.

(37) Kister, G.; Cassanas, G.; Vert, M. Polymer 1998, 39, 267.

(38) Liu, W.; Ni, Y.; Xiao, H. J. Colloid Interface Sci. 2004, 275, 584.

(39) Socrates, G. Infrared and raman characteristics group frequencies: Tables and Charts, John Wiley and sons: New York, NY, 2004. 

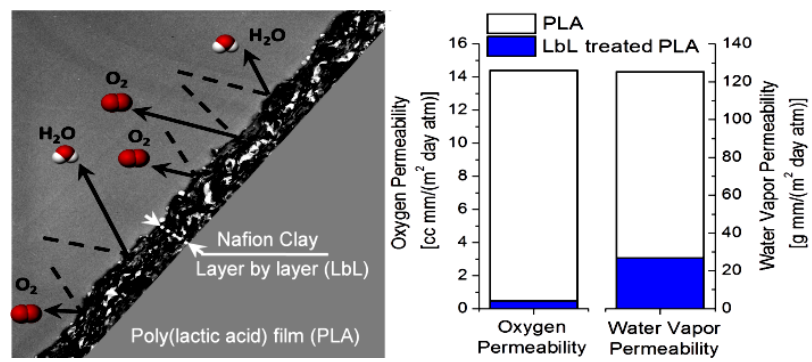